\title{
A study of serum phosphate levels and its correlation with curb-65 score in community acquired pneumonia
}

\author{
Nitish Ashok Gurav ${ }^{1}$, Avinash Hanbe Rajanna ${ }^{2}$, Sharana Basava Hoskera ${ }^{3}$, \\ Raveendra $\mathrm{KR}^{4}$ \\ ${ }^{1}$ Senior Resident, ${ }^{2,3}$ Assistant Professor, ${ }^{4}$ Professor, Department of Medicine, Bangalore Medical College and Research \\ Institute, KR road, Bangalore, Karnataka, India
}

Background: Community acquired pneumonia (CAP) refers to pneumonia contracted by a person with little or no contact with health care system. Phosphorus is an essential molecule in ATP, playing a central role in energy production. A normal range is 2.5 to $4.5 \mathrm{mg} / \mathrm{dl}$. Phosphate disturbance are noted in patients with pneumonia. Hypophosphatemia, plays a role in impairing chemotaxis, phagocytosis and bactericidal activity of macrophages. Hyperphosphatemia in pneumonia result in hypocalcaemia and pulmonary calcification. Hence study of serum phosphate levels in community acquired pneumonia is of clinical significance. Aims and Objective: The was aimed to estimate the levels of serum phosphate in patients with community acquired pneumonia and to correlate serum phosphate levels with CURB 65 severity score. Materials and Methods: Seventy-five CAP patients admitted as inpatients are included in this study. Chest $X$ ray is obtained in all suspected cases. Serum phosphate levels are determined through blood investigation on Day 1 and Day 3. Results: Serum phosphate levels on Day 1 and Day 3 were significantly associated with CURB65 score. Both high and low phosphate levels were associated with high CURB 65 score. The association between phosphate levels and CURB 65 score was significant in patients who got discharged but not in patients who expired. Conclusions: Present study of serum phosphate levels as biomarkers in CAP showed that both hypophosphatemia and hyperphosphatemia carried poor prognosis which correlated with high CURB65 score.

Key words: Community acquired pneumonia; CURB65; Hypophosphatemia; Hyperphosphatemia; COPD

\section{INTRODUCTION}

Community acquired pneumonia refers to pneumonia contracted by a person with little or no contact with health care system. Groups with highest risk of morbidity and mortality with CAP include infants, elderly and ICS. Predisposed by COPD, smoking, diabetes and structural lung disease etc. The risk factors for early deterioration in community acquired pneumonia are hypoalbuminemia, neutropenia, thrombocytopenia, hyponatremia, hypoglycemia, multilobar infiltrates, severe hypoxemia (SPO2 <90), mental confusion, severe tachypnea.

\section{Access this article online}

Website:

http://nepjol.info/index.php/AJMS

DOI: 10.3126/ajms.v12i5.34108

E-ISSN: 2091-0576

P-ISSN: 2467-9100

Copyright (c) 2021 Asian Journal of Medical Sciences

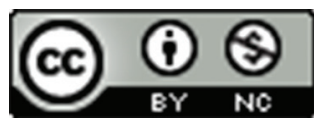

This work is licensed under a Creative Commons Attribution-NonCommercial 4.0 International License. 
generally 2.5 to $4.5 \mathrm{mg} / \mathrm{dl}$. Phosphate disturbance are noted in patients with pneumonia. Hypophosphatemia, which plays a role in impairing chemotaxis, phagocytosis and bactericidal activity of macrophages. Fisher et al found that hypophosphatemia is associated with longer hospital stay. ${ }^{3}$

Hyperphosphatemia in pneumonia is less widely studied and may result in hypocalcemia and pulmonary calcification. Saldias et al showed that hyperphosphatemia as a poor prognostic indicator in pneumonia. ${ }^{4}$ Di Marco et al have reported that high phosphorus levels can impair endothelial cell function at several levels including induction of sustained stiffening, increased apoptosis, impaired angiogenesis, impaired cell migration, downregulation of extracellular annexin II expression and shedding of endothelial microparticles. ${ }^{5}$ Hence study of serum phosphate levels in community acquired pneumonia is of clinical significance

\section{Aims and Objective}

The was aimed to estimate the levels of serum phosphate in patients with community acquired pneumonia and to correlate serum phosphate levels with CURB65 severity score.

\section{MATERIALS AND METHODS}

A total of 75 patients from those attending medicine OPD and getting admitted in medicine ward, Victoria \&Bowring hospital, attached to Bangalore medical college and research institute, during the period of November 1 st 2016 to august $30^{\text {th }} 2018$ will be taken for study, satisfying the inclusion and exclusion criteria.

\section{Inclusion criteria}

1. Patients willing to give written informed consent

2. Infiltrate on chest $\mathrm{X}$ ray taken at the time of admission

3. Presence of one or more major finding (cough with mucopurulent or hemoptic sputum, axillary temperature $>37.5$ degree celsius)

4. Presence of at least one minor finding (pleuritic chest pain, dyspnea, decreased level of consciousness, WBC $>12000$ cells/cum)

\section{Exclusion criteria}

1. Age $<18$ yrs

2. Transferred from another hospital

3. Prior hospitalization within a duration of 30 days

4. Hospital acquired pneumonia

5. Patients with deranged RFT or any other conditions causing change in phosphate, calcium levels

All clinically diagnosed pneumonia patients requiring hospitalization based on CURB 65 scores were admitted and chest X ray proven cases were taken into this study. Before taking into the study, all patients had signed the informed consent.

Routine hematological investigations along with serum calcium and phosphate levels on day 1 and day 3, chest $\mathrm{X}$ - ray were carried out. Patients were clinically assessed on day 1 and day 3 and their pulse, blood pressure, respiratory rate, temperature, sensorium level, signs of dehydration were noted.

The lab values of serial serum phosphate levels, total counts and vital signs were analyzed with the clinical profile and outcome in these study groups. The data was compiled \& appropriate statistical tests were applied.

$$
\text { Sample size: } \begin{aligned}
\mathrm{n} & =\frac{(4 \mathrm{pq})}{\mathrm{d}^{2}} \\
\mathrm{n} & =\frac{(4 * 72 * 28)=70.43}{10.7^{2}}
\end{aligned}
$$

$\mathrm{n}=75$ (round off)

\section{Statistical analysis}

The data was entered in Microsoft excel sheet and was analysed using SPSS version 22 software. The categorical data was represented in the form of frequency and percentage. Chi square test/Fisher's exact test was used to test the significance for qualitative data. Continuous data was represented as mean and standard deviation. $\mathrm{p}$ value $<0.05$ was considered as significant

\section{RESULTS}

\section{Age and sex distribution of patients}

In the present study, majority of the study subjects belonged to the age group $<45(33.3 \%)$, followed by $24 \%$ in the age group $65-74$ years and Males (53.3\%) outnumbered females (46. $7 \%$ ).

\section{Co morbidities and risk factors}

Out of the total study subjects, $42.6 \%$ of patients had no significant co morbidity. Twenty-nine point three percent of patients were diabetic, $16 \%$ patients were hypertensive, $14.6 \%$ had both diabetes and hypertension, $14.6 \%$ had COPD, $10.6 \%$ patients had retroviral disease, $10.6 \%$ patients had other co morbidities like old pulmonary tuberculosis, malignancy, interstitial lung disease and ischemic heart disease etc. $46.6 \%$ of patients were chronic smokers, which goes with the well-known fact that smoking is an important risk factor for community acquired pneumonia 
Clinical Parameters of patients

Evaluation of vital data at the time of admission and on day 3 was recorded. The mean pulse rate of the study subjects on day 1 and day 3 was $102.96+15.087$ and 99.85 +15.895 respectively. The mean difference between the two pulse rate readings was $3.107+15.470$. The mean difference between the pulse rates with respect to time was not significant $(p-0.086)$.

The systolic blood pressure of the study subjects on day 1 and day 3 was $118.13+33.216$ and $116.08+22.473$ respectively. The mean difference between the two systolic blood pressure readings was $2.053+19.430$. The mean difference between the systolic blood pressures with respect to time was not significant ( $\mathrm{p}-0.363)$.

The diastolic blood pressure of the study subjects on day 1 and day 3 was 76.59+16.723 and 77.28 +10.073 respectively. The mean difference between the two diastolic blood pressure readings was $-0.693+13.741$. The mean difference between the diastolic blood pressures with respect to time was not significant ( $p-0.663)$.

The mean respiratory rate of the study subjects on day 1 and day 3 was $32.49+4.944$ and $30.15+5.056$ respectively. The mean difference between the two respiratory rate readings was $2.347+3.108$. The mean difference between the respiratory rates with respect to time was significant $(\mathrm{p}-0.001)$.

Majority of the study subjects had haemoglobin greater than $12 \mathrm{gm} / \mathrm{dl}$ (46.7\%), followed by10.01 - $11.99 \mathrm{gm} / \mathrm{dl}$ (24\%) (Table 1).

Table 2 is presenting the association between TLC and CURB 65 score. It can be seen that the Curb 65 scores were high in the study subjects who had TLC $>11,000(>$ $50 \%$ ) (Table 2). There was no statistical significance found between TLC and Curb 65score ( $p-0.186)$.

Majority of the study subjects had urea levels in the range of $10-38 \mathrm{mg} / \mathrm{dl}(50.7 \%)$, followed by $38.01-50 \mathrm{mg} / \mathrm{dl}$ $(30.7 \%)$ and $>50 \mathrm{mg} / \mathrm{dl}(18.7 \%)$ (Table 3).

\section{Phosphate Day 1 with CURB 65}

The mean phosphate value on day 1 was high in patients who had CURB 65 score of $1(3.79+0.43)$, followed by CURB 65 score of $0,2,3$ and $4(3.59+0.76),(3.45+0.56)$, $(3.32+1.27)$ and $(2.70+1.05)$. The $t$ test results showed that there was significant difference between the CURB65 scores and phosphate levels $(\mathrm{p}-0.02)$ (Figure 1).

\section{Phosphate Day 3 v/s CURB 65}

The mean PO4 value on day 3 was high in patients who had CURB 65 score of $1(3.79+0.36)$, followed by CURB 65 score of $0,3,2$ and $4(3.78+0.66),(3.34+1.27),(3.18+$ $0.61)$ and $(2.61+0.75)$ (Table 2$)$. The t test results showed that there was significant difference between the CURB65 scores and phosphate levels ( $p-0.002)$.

\section{Phosphate - Average v/s CURB 65}

The mean of Phosphate value was high in patients who had CURB 65 score of $1(3.93+0.27)$, followed by CURB 65 score of $0,3,2$ and $4(3.88+0.64),(3.23+1.23),(3.18+$ $0.60)$ and $(2.60+0.82)$ (Figure 3$)$. The t test results showed that there was significant difference between the CURB65 scores and phosphate levels ( $p-0.001)$.

The graphs present the association between phosphate levels, outcome of the study subjects and CURB 65 score. It can be observed that as the phosphate levels are increasing or decreasing, the CURB 65 score increases. Study subjects who had phosphate levels $<2.5 \mathrm{mg} / \mathrm{dl}$, presented with CURB 65 Score as 4 (45\%). Similarly, the study subjects with high phosphate levels ( $>5 \mathrm{mg} / \mathrm{dl}$ ) had CURB 65 scores as $3(22.7 \%)$. The association between phosphate

\begin{tabular}{lcc}
$\begin{array}{l}\text { Table 1: Hemoglobin }(\mathbf{g} / \mathbf{d l}) \text { values in patients } \\
\text { study patients }\end{array}$ & \\
\hline Hemoglobin & Frequency & Percent \\
\hline$<9$ & 11 & 14.7 \\
$9-10$ & 11 & 14.7 \\
$10.01-11.99$ & 18 & 24.0 \\
$>12$ & 35 & 46.7 \\
Total & 75 & 100.0 \\
\hline
\end{tabular}

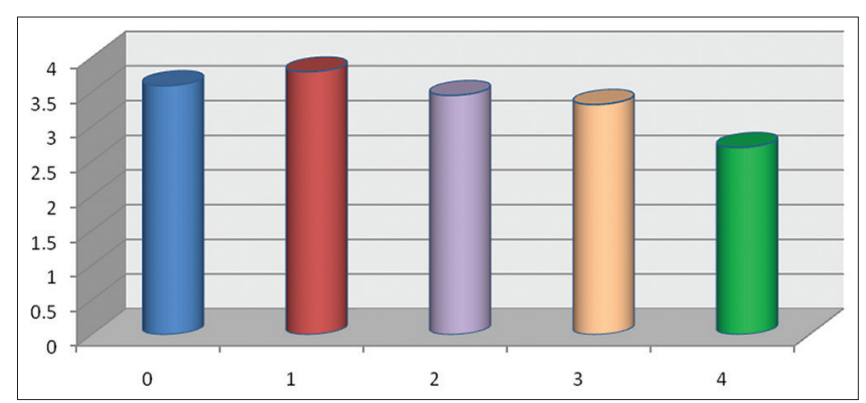

Figure 1: Phosphate Day 1 with CURB 65

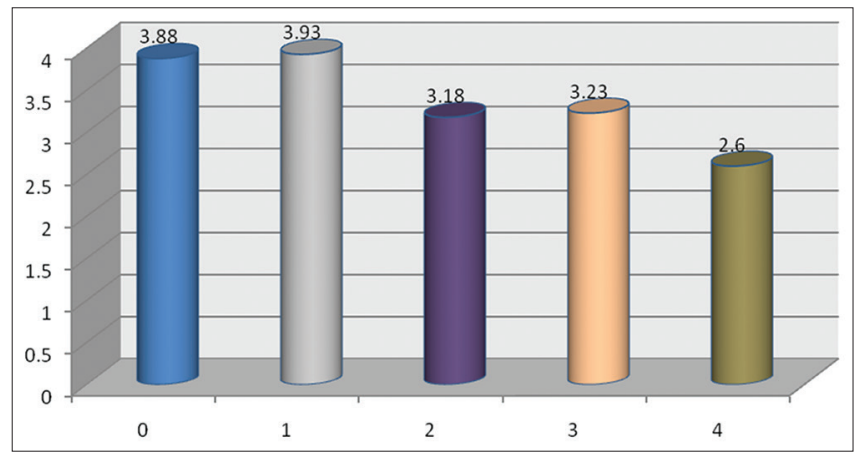

Figure 2: Phosphate Day 3 v/s CURB 65 


\begin{tabular}{|c|c|c|c|c|c|c|c|}
\hline \multirow[t]{2}{*}{ TLC } & \multicolumn{5}{|c|}{ CURB 65} & \multirow[t]{2}{*}{ Total } & \multirow[t]{2}{*}{$p$ value } \\
\hline & 0 & 1 & 2 & 3 & 4 & & \\
\hline \multirow[t]{2}{*}{$<4000$} & 0 & 0 & 0 & 2 & 0 & 2 & \multirow[t]{8}{*}{0.186} \\
\hline & $0.0 \%$ & $0.0 \%$ & $0.0 \%$ & $9.1 \%$ & $0.0 \%$ & $2.7 \%$ & \\
\hline \multirow[t]{2}{*}{$4000-11000$} & 4 & 7 & 5 & 7 & 3 & 26 & \\
\hline & $50.0 \%$ & $50.0 \%$ & $45.5 \%$ & $31.8 \%$ & $15.0 \%$ & $34.7 \%$ & \\
\hline \multirow[t]{2}{*}{$>11000$} & 4 & 7 & 6 & 13 & 17 & 47 & \\
\hline & $50.0 \%$ & $50.0 \%$ & $54.5 \%$ & $59.1 \%$ & $85.0 \%$ & $62.7 \%$ & \\
\hline \multirow[t]{2}{*}{ Total } & 8 & 14 & 11 & 22 & 20 & 75 & \\
\hline & $100.0 \%$ & $100.0 \%$ & $100.0 \%$ & $100.0 \%$ & $100.0 \%$ & $100.0 \%$ & \\
\hline
\end{tabular}

\begin{tabular}{lcc}
$\begin{array}{l}\text { Table 3: Urea }(\mathrm{mg} / \mathrm{l}) \\
\text { on admission }\end{array}$ & distribution patients studied \\
\hline Urea $(\mathbf{m g} / \mathrm{dl})$ & Frequency & Percent \\
\hline $10-38$ & 38 & 50.7 \\
$38.01-50$ & 23 & 30.7 \\
$>50$ & 14 & 18.7 \\
Total & 75 & 100.0 \\
\hline
\end{tabular}

levels among discharged study subjects and CURB 65 scores was significant $(\mathrm{p}<0.001)$ but The association between phosphate levels among study subjects who died and CURB 65 scores was not significant $(p-0.087)$ (Table 4).

The table shows the association between $\mathrm{S}$. albumin and CURB 65 scores. $50 \%$ of the study subjects had S. albumin in the range of $1.04-2.4$ and CURB 65 score of 4 . Among the study subjects with $\mathrm{S}$. albumin in the range of 2.5-3.5 mg/dl, 59.1\% had CURB 65 score of 3, followed by $40 \%$ (CURB 65 - 4) and 36.4\% (CURB 65 - 3) (Table 5). Those who had normal albumin levels (3.6-6.8) had less CURB 65 scores. Chi square test results showed that the association between s. albumin and CURB 65 Scores are statistically significant $(p-0.003)$.

Single lobe involvement was seen in high number (68\%). More than one lobe involvement was seen in $32 \%$ of the study subjects. The CURB 65 scores were high in number in single lobe involvement except with CURB 65 Score of 4 where the study subjects had more than one lobe involvement $(60 \%)$. The association between CURB 65 scores and Chest $\mathrm{X}$ ray findings was significant ( $\mathrm{p}-$ 0.007) (Table 6).

\section{DISCUSSION}

CAP is the second most common cause of death from infectious diseases in India and the leading cause of childhood mortality. The 2014 World Health Organization Global Burden of Disease Study shows global burden of LRTIs, were 429.2 million episodes of illness which included CAP. It shows 94.5 million disability adjusted life years (DALYs) in adults aged over 59 years, with an annual

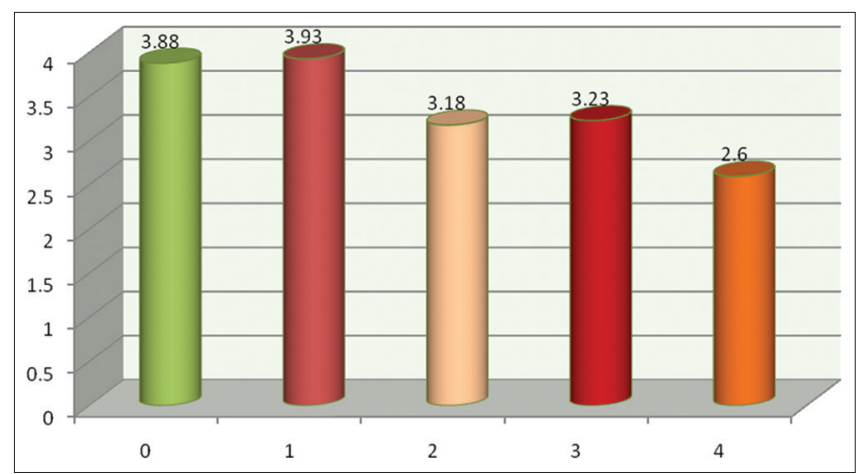

Figure 3: Phosphate - Average v/s CURB 65

mortality of 1.6 million. ${ }^{4}$ Hypophosphatemia plays a role in impairing chemotaxis, phagocytosis and bactericidal activity of macrophages, Vivian Barak MD et al studied hypophosphatemia in sepsis and infection. The study showed that $80 \%$ of patients had hypophosphatemia associated with high levels of TNF alpha, IL6. The study demonstrated relationship between high levels of inflammatory cytokines and their receptors and serum phosphate levels especially in patients with positive blood culture. $^{6}$

Our study included age groups above 18yrs. Majority of the study subjects belonged to the age group $<45$ years $(33.3 \%)$, followed by the age group $65-74$ years $(24 \%)$. Least number of subjects were in age group $>75$ years. Males (53.3\%) outnumbered females (46.7\%) in the present study.

Out of the total study subjects, $42.6 \%$ of patients had no significant co morbidity. $29.3 \%$ of patients were diabetic, $16 \%$ patients were hypertensive, $14.6 \%$ had both diabetes and hypertension, $14.6 \%$ had COPD, $10.6 \%$ patients had retroviral disease, $10.6 \%$ patients had other co morbidities like old pulmonary tuberculosis, malignancy, interstitial lung disease and ischemic heart disease etc. $46.6 \%$ of patients were chronic smokers, which goes with the well-known fact that smoking is an important risk factor for community acquired pneumonia and most of these patients having history of smoking for 5-10 year. 


\begin{tabular}{|c|c|c|c|c|c|c|c|c|}
\hline \multirow[t]{2}{*}{ Outcome } & \multirow[t]{2}{*}{ phosphate } & \multicolumn{6}{|c|}{ CURB 65} & \multirow[t]{2}{*}{$p$ value } \\
\hline & & 0 & 1 & 2 & 3 & 4 & Total & \\
\hline \multirow[t]{10}{*}{ Discharged } & $<2.5$ & 0 & 0 & 1 & 6 & 4 & 11 & 0.001 \\
\hline & & $0.0 \%$ & $0.0 \%$ & $9.1 \%$ & $33.3 \%$ & $33.3 \%$ & $17.5 \%$ & \\
\hline & $2.5-3.5$ & 3 & 4 & 7 & 9 & 8 & 31 & \\
\hline & & $37.5 \%$ & $28.6 \%$ & $63.6 \%$ & $50.0 \%$ & $66.7 \%$ & $49.2 \%$ & \\
\hline & $3.51-5$ & 5 & 10 & 3 & 1 & 0 & 19 & \\
\hline & & $62.5 \%$ & $71.4 \%$ & $27.3 \%$ & $5.6 \%$ & $0.0 \%$ & $30.2 \%$ & \\
\hline & $>5$ & 0 & 0 & 0 & 2 & 0 & 2 & \\
\hline & & $0.0 \%$ & $0.0 \%$ & $0.0 \%$ & $11.1 \%$ & $0.0 \%$ & $3.2 \%$ & \\
\hline & Total & 8 & 14 & 11 & 18 & 12 & 63 & \\
\hline & & $100.0 \%$ & $100.0 \%$ & $100.0 \%$ & $100.0 \%$ & $100.0 \%$ & $100.0 \%$ & \\
\hline \multirow{10}{*}{ Death } & $<2.5$ & 0 & 0 & 0 & 1 & 5 & 6 & 0.087 \\
\hline & & $0.0 \%$ & $0.0 \%$ & $0.0 \%$ & $25.0 \%$ & $62.5 \%$ & $50.0 \%$ & \\
\hline & $2.5-3.5$ & 0 & 0 & 0 & 0 & 2 & 2 & \\
\hline & & $0.0 \%$ & $0.0 \%$ & $0.0 \%$ & $0.0 \%$ & $25.0 \%$ & $16.7 \%$ & \\
\hline & $3.51-5$ & 0 & 0 & 0 & 0 & 0 & 0 & \\
\hline & & $0.0 \%$ & $0.0 \%$ & $0.0 \%$ & $0.0 \%$ & $0.0 \%$ & $0.0 \%$ & \\
\hline & $>5$ & 0 & 0 & 0 & 3 & 1 & 4 & \\
\hline & & $0.0 \%$ & $0.0 \%$ & $0.0 \%$ & $75.0 \%$ & $12.5 \%$ & $33.3 \%$ & \\
\hline & Total & 0 & 0 & 0 & 4 & 8 & 12 & \\
\hline & & $0.0 \%$ & $0.0 \%$ & $0.0 \%$ & $100.0 \%$ & $100.0 \%$ & $100.0 \%$ & \\
\hline \multirow[t]{10}{*}{ Total } & $<2.5$ & 0 & 0 & 1 & 7 & 9 & 17 & 0.000 \\
\hline & & $0.0 \%$ & $0.0 \%$ & $9.1 \%$ & $31.8 \%$ & $45.0 \%$ & $22.7 \%$ & \\
\hline & $2.5-3.5$ & 3 & 4 & 7 & 9 & 10 & 33 & \\
\hline & & $37.5 \%$ & $28.6 \%$ & $63.6 \%$ & $40.9 \%$ & $50.0 \%$ & $44.0 \%$ & \\
\hline & $3.51-5$ & 5 & 10 & 3 & 1 & 0 & 19 & \\
\hline & & $62.5 \%$ & $71.4 \%$ & $27.3 \%$ & $4.5 \%$ & $0.0 \%$ & $25.3 \%$ & \\
\hline & $>5$ & 0 & 0 & 0 & 5 & 1 & 6 & \\
\hline & & $0.0 \%$ & $0.0 \%$ & $0.0 \%$ & $22.7 \%$ & $5.0 \%$ & $8.0 \%$ & \\
\hline & Total & 8 & 14 & 11 & 22 & 20 & 75 & \\
\hline & & $100.0 \%$ & $100.0 \%$ & $100.0 \%$ & $100.0 \%$ & $100.0 \%$ & $100.0 \%$ & \\
\hline
\end{tabular}

\section{Table 5: Correlation between CURB65, Albumin levels and outcome}

\begin{tabular}{|c|c|c|c|c|c|c|c|}
\hline \multirow[t]{2}{*}{ S.Albumin } & \multicolumn{5}{|c|}{ CURB 65} & \multirow[t]{2}{*}{ Total } & \multirow[t]{2}{*}{ P value* } \\
\hline & 0 & 1 & 2 & 3 & 4 & & \\
\hline $1.04-2.4$ & $\begin{array}{c}1 \\
\end{array}$ & $\begin{array}{c}2 \\
143 \%\end{array}$ & 1 & $\begin{array}{c}7 \\
318 \%\end{array}$ & 10 & 21 & 0.003 \\
\hline $2.5-3.5$ & 2 & 4 & 4 & 13 & 8 & 31 & \\
\hline $3.6-6.8$ & $\begin{array}{c}25.0 \% \\
5\end{array}$ & $\begin{array}{c}28.6 \% \\
8\end{array}$ & $\begin{array}{c}36.4 \% \\
6\end{array}$ & $\begin{array}{c}59.1 \% \\
2\end{array}$ & $\begin{array}{c}40.0 \% \\
2\end{array}$ & $\begin{array}{c}41.3 \% \\
23\end{array}$ & \\
\hline Total & $\begin{array}{c}8 \\
100.0 \%\end{array}$ & $\begin{array}{c}14 \\
100.0 \%\end{array}$ & $\begin{array}{c}11 \\
100.0 \%\end{array}$ & $\begin{array}{c}22 \\
100.0 \%\end{array}$ & $\begin{array}{c}20 \\
100.0 \%\end{array}$ & $\begin{array}{c}30.7 \% \\
75 \\
100.0 \%\end{array}$ & \\
\hline
\end{tabular}

*Chi square test

\begin{tabular}{|c|c|c|c|c|c|c|c|}
\hline \multirow[t]{2}{*}{ CXR } & \multicolumn{5}{|c|}{ CURB 65} & \multirow[t]{2}{*}{ Total } & \multirow[t]{2}{*}{$p$ value } \\
\hline & 0 & 1 & 2 & 3 & 4 & & \\
\hline Single lobe involvement & $\begin{array}{c}6 \\
75.0 \%\end{array}$ & $\begin{array}{c}13 \\
929 \%\end{array}$ & $\begin{array}{c}10 \\
0\end{array}$ & $\begin{array}{c}14 \\
636 \%\end{array}$ & $\begin{array}{c}8 \\
40 \%\end{array}$ & 51 & $0.007^{*}$ \\
\hline$>1$ lobe involvement & 2 & 1 & 1 & 8 & 12 & 24 & \\
\hline & $25.0 \%$ & $7.1 \%$ & $9.1 \%$ & $36.4 \%$ & $60.0 \%$ & $32.0 \%$ & \\
\hline Total & $\begin{array}{c}8 \\
100.0 \%\end{array}$ & $\begin{array}{c}14 \\
100.0 \%\end{array}$ & $\begin{array}{c}11 \\
100.0 \%\end{array}$ & $\begin{array}{c}22 \\
100.0 \%\end{array}$ & $\begin{array}{c}20 \\
100.0 \%\end{array}$ & $\begin{array}{c}75 \\
100.0 \%\end{array}$ & \\
\hline
\end{tabular}

*chi-square test

Majority of the study subjects had hemoglobin greater than $12 \mathrm{gm} / \mathrm{dl}(46.7 \%)$, followed by10.01 - $11.99 \mathrm{gm} / \mathrm{dl}(24 \%)$.
It was observed that the CURB 65 scores were high in the study subjects who had TLC $>11,000 .(>50 \%)$ There was 
no statistical significance found between TLC and CURB 65 score $(p-0.186)$.

Urea levels in majority of the study subjects were in the range of $10-38 \mathrm{mg} / \mathrm{dl}(50.7 \%)$, followed by 38.01 - $50 \mathrm{mg} / \mathrm{dl}(30.7 \%)$ and $>50 \mathrm{mg} / \mathrm{dl}(18.7 \%)$. In a study on adult patients with pneumonia at Papua New Guinea showed elevation of blood urea levels in 55\% of bacteraemia and $26 \%$ of non-bacteraemia pneumonia. This observation was more so in patients with extensive consolidation and the cause was attributed to both pre renal and renal mechanisms causing elevated blood urea levels. ${ }^{7}$

\section{Phosphate levels and CURB 65 scores}

The mean phosphate value on day 1 was high in patients who had CURB 65 score of $1(3.79+0.43)$, followed by CURB 65 score of $0,2,3$ and $4(3.59+0.76),(3.45+0.56)$, $(3.32+1.27)$ and $(2.70+1.05)$. The $t$ test results showed that there was significant difference between the CURB 65 scores and phosphate levels $(p-0.02)$.

The mean phosphate value on day 3 was high in patients who had CURB 65 score of $1(3.79+0.36)$, followed by CURB 65 score of $0,3,2$ and $4(3.78+0.66),(3.34+1.27)$, $(3.18+0.61)$ and $(2.61+0.75)$. The $t$ test results showed that there was significant difference between the CURB 65 scores and phosphate levels $(p-0.002)$.

The mean of phosphate value of Day 1 and Day 3 was high in patients who had CURB 65 score of $1(3.93+0.27)$, followed by CURB 65 score of $0,3,2$ and $4(3.88+0.64)$, $(3.23+1.23),(3.18+0.60)$ and $(2.60+0.82)$. The t test results showed that there was significant difference between the CURB 65 scores and phosphate levels ( $p-0.001)$.

Mohammad E. Naffaa et al studied 3876 patients in Rambam Health Care Campus with community acquired pneumonia. Severe hyperphostemia is associated with increased mortality. Higher CURB65 is associated with hyperphosphatemia and hypophosphatemia with significant $\mathrm{p}$ value of $<0.0001{ }^{8}$

\section{Correlation between CURB65, Phosphate levels and outcome}

On comparing the association between phosphate levels, outcome of the study subjects and CURB 65 score, it was observed that as the phosphate levels are increasing or decreasing, the CURB 65 score increases. Study subjects who had phosphate levels $<2.5 \mathrm{mg} / \mathrm{dl}$, presented with CURB 65 Score as 4 (45\%). Similarly, the study subjects with high phosphate levels $(>5 \mathrm{mg} / \mathrm{dl}$ ) had CURB 65 scores as $3(22.7 \%)$. The association between phosphate levels among discharged study subjects and CURB 65 scores was significant $(\mathrm{p}<0.001)$ but the association between phosphate levels among study subjects who died and CURB 65 scores was not significant $(\mathrm{p}-0.087)$.

Ramkumar T. Sankaran MD et al studied 302 patients admitted to Long Jewish Medical Centre. Serum phosphates levels on admission and 4 days before onset of pneumonia were done. Hypophosphatemic patients had longer hospital stay and mortality compared to normophosphatemic patients. The study also concluded that pneumonia was associated with hypocalcemia, hypophosphatemia and hypoalbuminemia. ${ }^{9}$

C Feldman, J.M. Kallenbach et al conducted retrospective study of 73 patients of CAP. The study compared various clinical features with initial lab investigations. A lower total WBC count, high creatinine and high phosphate levels had poor prognosis. In these patients the mortality rate remained high despite advanced antibiotic usage and ICU care. $^{10}$

Comparison chest $\mathrm{X}$ ray features and CURB 65 score Single lobe involvement was seen in high number $(68 \%)$. More than one lobe involvement was seen in $32 \%$ of the study subjects. The CURB 65 scores were high in number in single lobe involvement except with CURB 65 Score of 4 where the study subjects had more than one involvement $(60 \%)$. The association between CURB 65 scores and Chest $\mathrm{X}$ ray findings was significant $(\mathrm{p}-0.007)$. In a study done by Mustafa el-Ebiary et al. on community acquired pneumonia patients showed that the extent of Chest $\mathrm{X}$ ray infiltration was one of many significant prognostic indicators in CAP. ${ }^{11}$ In a study by $\mathrm{R}$ Riquelme et al. showed poor prognosis in CAP in patients who were bedridden, high temperature and respiratory rate at admission and three or more lobes (multilobar) involvement on chest Xray. ${ }^{12}$

Comparison between ICU admissions and outcome Among the study subjects, $73 \%$ were discharged who had no ICU admission, whereas $91.7 \%$ of the study subjects died who had ICU admission. The association between ICU admission and outcome was significant $(\mathrm{p}-0.000)$.

\section{CONCLUSION}

Present study of serum phosphate levels as biomarkers in CAP showed that both hypophosphatemia and hyperphosphatemia carried poor prognosis which correlated with high CURB65 score. Normal phosphate levels in CAP patients had low CURB65 score and carried better prognosis. Patients who had diabetes, COPD, retroviral disease, smoking etc. had significant risk of developing CAP according to the study. 


\section{Limitation}

Sample size was small and single centre study

\section{ACKNOWLEDGEMENT}

The authors take this opportunity to thank Department of Medicine for their whole hearted support for this study

\section{REFERENCES}

1. Kasper D, Fauci A, Hauser S, Longo D, Jameson J and Loscalzo J. Harrison's Principles of Internal Medicine. New York: McGraw-Hill Professional Publishing; 2015:804-809

2. API Textbook of MEDICINE. 9th ed. The Association of Physicians of India; 2012: 1721-1723

3. Fisher J, Magid N, Kallman C, Fanucchi M, Klein L, McCarthy D, et al. Respiratory IIIness and Hypophosphatemia. Chest. 1983; 83:504-508.

https://doi.org/10.1378/chest.83.3.504

4. Saldías Peñafiel F, O'Brien Solar A, Gederlini Gollerino A, Farías Gontupil G and Díaz Fuenzalida A. Community-acquired pneumonia requiring hospitalization in immunocompetent elderly patients: clinical features, prognostic factors and treatment. Arch Bronconeumol. 2003; 39(8):333-340.

https://doi.org/10.1016/S0300-2896(03)75400-3

5. Di Marco GS, Konig M and Stock C. High phosphate directly affects endothelial function by downregulating annexin II. Kidney Int. 2013; 83(2):213-222.

https://doi.org/10.1038/ki.2012.300

6. Shibl A, Memish Z, Ibrahim E and Kanj S. Burden of adult community-acquired pneumonia in the Middle East/North Africa region. Reviews in Medical Microbiology. 2010; 21:11-20.

https://doi.org/10.1097/MRM.0b013e3283377af7

7. Barak V, Schwartz A, Kalickman I, Nisman B, Gurman G and Shoenfeld Y. Prevalence of Hypophosphatemia in Sepsis and Infection: The Role of Cytokines. The American Journal of Medicine. 1998; 104:40-47.

https://doi.org/10.1016/S0002-9343(97)00275-1

8. Douglas $R$, Devitt $L$ and Macartney B. Elevation of Serum Bilirubin and Blood Urea in Pneumonia. Australian and New Zealand Journal of Medicine. 1974; 4:346-351. https://doi.org/10.1111/j.1445-5994.1974.tb03202.x

9. Naffaa M, Mustafa M, Azzam M, Nasser R, Andria N, Azzam Z, et al. Serum inorganic phosphorus levels predict 30-day mortality in patients with community acquired pneumonia. BMC Infectious Diseases. 2015; 15. https://doi.org/10.1186/s12879-015-1094-6

10. Sankaran R, Mattana J, Pollack S, Bhat P, Ahuja T, Patel A, et al. Laboratory Abnormalities in Patients With Bacterial Pneumonia. Chest. 1997; 111: 595-600. https://doi.org/10.1378/chest.111.3.595

11. EL-Ebiary M, Sarmiento X, Torres A, Nogue S, Messalles E, Bodi M, et al. Prognostic Factors of SevereLegionellaPneumonia Requiring Admission to ICU. American Journal of Respiratory and Critical Care Medicine. 1997; 156:1467-1472. https://doi.org/10.1164/ajrccm.156.5.97-04039

12. Riquelme R, Torres A, El-Ebiary M, de la Bellacasa J, Estruch R, Mensa J, et al. Community-acquired pneumonia in the elderly: A multivariate analysis of risk and prognostic factors. American Journal of Respiratory and Critical Care Medicine. 1996; 154:1450-1455

https://doi.org/10.1164/ajrccm.154.5.8912763

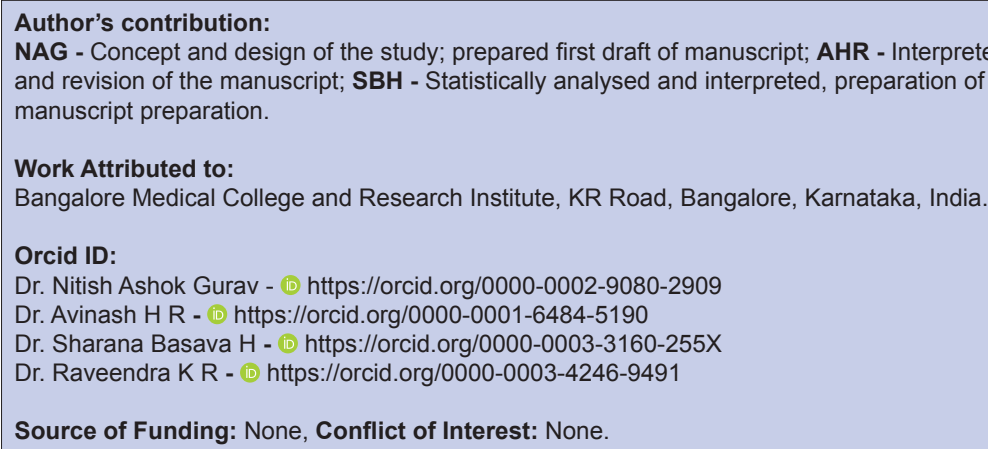

